\title{
L. On a mechanical violin-player for acoustical experiments
}

\section{C.V. Raman M.A.}

To cite this article: C.V. Raman M.A. (1920) L. On a mechanical violin-player for acoustical experiments, Philosophical Magazine Series 6, 39:233, 535-536, DOI: $10.1080 / 14786440508636065$

To link to this article: http://dx.doi.org/10.1080/14786440508636065

曲 Published online: 08 Apr 2009.

Submit your article to this journal $\pi$

Џ Article views: 11

Q View related articles $₫$

Citing articles: 2 View citing articles 
L. On a Mechanical Violin-Player for Acoustical Faperiments. By C. V. Raman, M.A., Palit Professor of Physics in the Calcutta University*.

[Plate XIV.]

TTHE accompanying illustration (Plate XIV.) and brief description of a mechanically-played violin which has been developed after considerable experimentation and used in a series of studies of the acoustics of bowed stringed instruments may be of interest to readers of the Philosophical Magazine. The apparatus has been designed to reproduce as closely as possible the conditions obtaining in ordinary musical practice. A violin and a horse-hair bow of the ordinary type are used, and the object is to enable the strings to be bowed with accurately controlled and measurable pressures and speeds. Pressures ranging from one or two grammes weight up to a hundred grammes or more, and speeds ranging from one or two centimetres per second up to lalf a metre per second or more could be obtained and determined.

The arrangement differs from the ordinary playing of the instrument in that the bow itself remains stationary and the violin is caused to move to and fro with uniform speed. The light wooden cradle on which the violin is mounted rests on a brass slide which moves noiselessly to and fro along a well-oiled cast-iron track. The necessary movement is obtained as shown in the Plate by means of an endless chain which carries a pin working in a vertical slot attached to the brass slide. The chain is stretched taut between two freewheels and is kept in movement by the rotation of one of the axles with fly-wheel and belt as shown in the Plate. By using a conical driving pulley on which the belt runs, various speeds of movement can be obtained. Very little power is of course required to drive the apparatus, but in order to obtain steady and uniform speeds over long intervals of time, it is advisable to use a shunt-wound motor with an ample margin of power running on little or no load in order to drive the apparatus. No special speed regulation will then be necessary.

The mounting of the bow demanded special attention in order that satisfactory results might be obtained. As can be seen in the Plate, it is attached to the end of a long wooden lath which is carefully balanced on an axle fitted with ballbearings in order to secure the necessary solidity and freedom

\footnotetext{
* Communicated by the Author.
} 


\section{Mechanical Violin-Player for Acoustical Experiments.}

of movement. A weight hanging freely at the shorter end of the lever balances the weight of the lath and the bow. An adjustment is provided by which the bow may be held obliquely so that fewer or more hairs may be made to touch the strings. A vertical adjustment of the axle is also possible by which it can be arranged that the hairs of the bow when at rest touching the strings should be exactly parallel to the cast-iron track on which the cradle of the violin slides. (This is very important for the successful working of the apparatus.) The block carrying the axle can also be moved parallel to the strings of the violin with the aid of a screw, so that the distance between the bridge and the point at which the bow touches the string may be expeditionsly altered. Finally, in order to check any movements of the lever carrying the bow which would result in fluctuations of its pressure, a damping arrangement is provided. A stout wire carrying a number of horizontal disks placed at intervals hangs freely from the shorter arm of the lever and dips in a beaker of water or light oil. This device ensures a very smooth and uniform bowing of the string, and is found to be quite successful in practice. A rider can be placed at any desired point on the graduated longer arm of the lever and provides the necessary means of adjustment of bowing pressure. The observations of the tone of the instrument are always made when the violin is at or near the middle point of its stroke, and quite definite values may be obtained of the minimum pressure necessary under any given conditions in order to elicit a sustained tone with a strongly marked fundamental.

A considerable variety of investigations can be carried out with the aid of the mechanical player described above. As examples may be mentioned the study of:- $(a)$ the relation between the bowing pressure and the position of the bowed point on the string; (b) the relation between bowing speed and bowing pressure; (c) the variation of bowing pressure with pitch, and the phenomena of the wolf-note; $(d)$ the effect of using a "mute" on the bowing pressure; (e) the quantitative relation between tone-intensity and pitch for different types of instrument. A detailed description of the experimental results obtained on these points, and of the various other applications of the mechanical player, will be given in a forthcoming publication of the Indian Association for the Cultivation of Science.

Calcutta,

17 th November, 1919. 
RAMAX.

Phil. Mag. Ser. 6. Vol. 39. Pl. XIV.

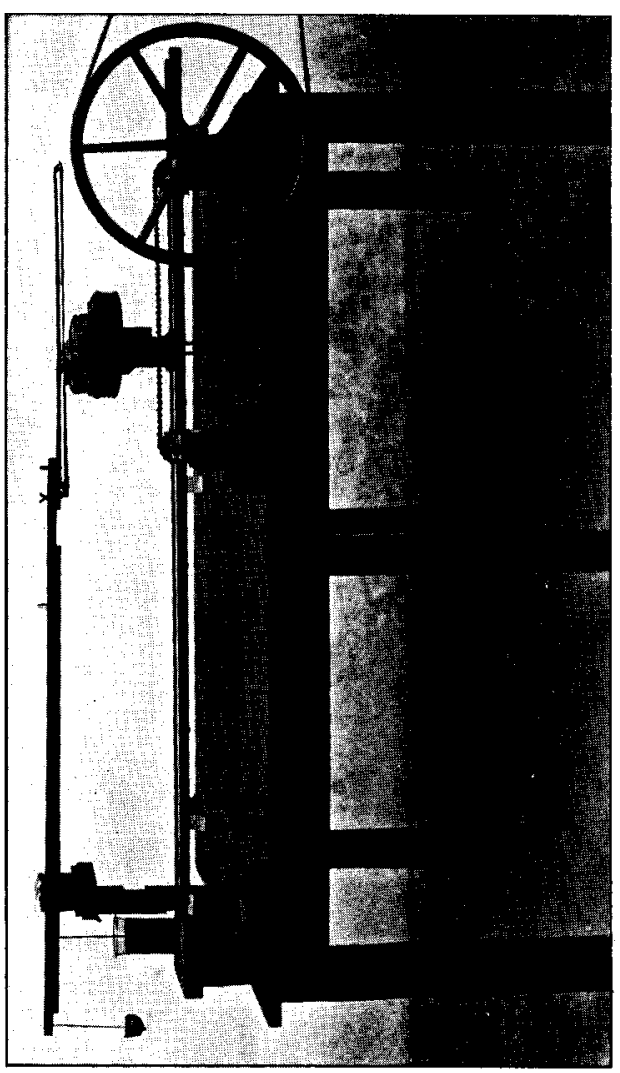

 